\title{
Postoperative fluid balance and outcomes after Pancreaticoduodenectomy: a retrospective study in 301 patients
}

\author{
Hang Zhang ${ }^{1} \cdot$ Yechen Feng $^{1} \cdot$ Duoji Suolang $^{1} \cdot$ Chao Dang $^{1} \cdot$ Renyi Qin $^{1}{ }^{10}$
}

Received: 25 April 2021 / Accepted: 16 January 2022 / Published online: 22 February 2022

(c) The Author(s) 2022

\begin{abstract}
Background The incidence of postoperative morbidity after pancreaticoduodenectomy (PD) is high; however, whether fluid management after surgery affects postoperative morbidity is unclear. This study aimed to determine whether fluid balance in patients undergoing PD is associated with postoperative complications and mortality.

Methods Data from a computer-based database of patients who underwent PD between 2016 and 2019 were retrospectively analyzed. Patients were stratified into four quartiles according to their fluid balance at $0-24,24-48,48-72$, and $72-96 \mathrm{~h}$ after surgery. The predefined primary outcome measures were morbidity and mortality rates.

Results A total of 301 patients were included. The morbidity and mortality rates in the cohort were $56.5 \%$ and $3.7 \%$, respectively. The most common complications after PD were postoperative pancreatic fistula (31.9\%) and delayed gastric emptying (31.6\%). Patients with a higher fluid balance in the 0-24-, 24-48-, and 48-72-h postoperative periods had a higher morbidity rate and longer hospital stay than those with a lower fluid balance (all $P<0.05$ ). Patients with a fluid balance of $4212 \mathrm{~mL}$ during the postoperative $0-72 \mathrm{~h}$ were most likely to develop complications $(P<0.001)$. The area under the receiver operating characteristic curve was $0.71(0.65-0.77)$, with a sensitivity of $58.24 \%$ and a specificity of $77.10 \%$.

Conclusions Higher postoperative fluid balance seems to be associated with increased morbidity after PD compared to lower fluid balance. Surgeons should pay close attention to the occurrence of complications in patients with a high fluid balance.
\end{abstract}

Keywords Fluid management $\cdot$ Pancreaticoduodenectomy $\cdot$ Whipple $\cdot$ Outcomes

\section{Introduction}

Pancreaticoduodenectomy (PD) remains one of the most challenging surgical procedures and has the highest complication rate among all abdominal surgical procedures. Although the perioperative mortality rate associated with PD has decreased in recent decades from $>20 \%$ to $<3 \%$, especially in high-volume centers [1], the morbidity rate remains high, ranging from $40 \%$ to $60 \%$ [2]. Considering the high complication rate, one of the principal goals of clinical

Chao Dang and Renyi Qin equally contributed to this work.

Renyi Qin

ryqin@tjh.tjmu.edu.cn

1 Department of Biliary-Pancreatic Surgery, Affiliated Tongji Hospital, Tongji Medical College, Huazhong University of Science and Technology, 1095 Jiefang Avenue, Wuhan 430030, Hubei, China research related to PD during the past few decades has been to reduce postoperative morbidity. The methods proposed to reduce morbidity after PD include the use of octreotide and its analogs or other pharmacologic agents, modifications in the type of surgical process, and variations in anastomotic methods [3-6]. Some of these techniques have improved the outcomes of PD, although others remain unsatisfactory. One largely unexplored strategy that has been proposed to reduce complications and improve outcomes after PD is control of perioperative fluid administration.

Perioperative fluid management can be challenging. The effects of third spacing and evaporative losses in decreasing extracellular fluid volume have led to the use of traditional aggressive intravenous fluid support, especially during complicated operations such as PD. [7] However, only a few studies have examined the impact of postoperative fluid balance on outcomes in this high-risk population of patients undergoing PD. Therefore, this retrospective study aimed to evaluate whether perioperative fluid administration is associated with the short-term outcomes after PD. 


\section{Methods}

Patients who underwent PD between April 2016 and February 2019 were retrospectively analyzed. The inclusion criterion was undergoing the PD procedure. Patients who underwent other surgical procedures because of metastasis or changes in the surgical plan (central pancreatectomy, distal pancreatectomy, or gastrojejunostomy) were excluded. A computer-based database was searched for data including age, sex, surgical procedure, pathologic characteristics, length of hospital stay, morbidity, and mortality. The body surface area was calculated using height and weight measurements. All surgical procedures were performed by a single experienced surgeon (RYQ). Fluid intake and output data were collected at 24, 48, 72, and $96 \mathrm{~h}$ postoperatively. Fluid balance was defined as the intake volume minus the output volume at each time interval. For analysis, patients were divided into quartiles according to the overall fluid balance during each time interval (0-24, 24-48, 48-72, and 72-96 h postoperatively). The predefined primary outcome measures were morbidity and mortality rates. Morbidities were graded using the Clavien-Dindo classification system [8]. Secondary outcome measures included hospital length of stay (LOS), intensive care unit (ICU) LOS, surgical-site or abdominal infection, delayed gastric emptying (DGE), postoperative pancreatic fistula (POPF), bile leakage, bowel leakage, acute kidney injury (AKI), major cardiopulmonary complications, and hospital readmission within 90 days after surgery. POPF was defined in accordance with the guidelines of the International Study Group of Pancreatic Fistula [9]. DGE was defined in accordance with the guidelines of the International Study Group of Pancreatic Surgery [10]. AKI was defined as a $50 \%$ increase in serum creatinine level from baseline. Systemic inflammatory response syndrome (SIRS) was defined in accordance with the definition of the American College of Chest Physicians/Society of Critical Care Medicine Consensus Conference [11]. Acute respiratory distress syndrome (ARDS) was defined in accordance with the Berlin definition [12]. The study was approved by the ethics committee of Tongji Hospital.

The summary statistics of the study population were tabulated. The area under the receiver operating characteristic curve of fluid input was calculated. The cutoff value of fluid input for identifying morbidity was obtained and evaluated for sensitivity and specificity. Statistical significance was set at $P<0.05$. Statistical analyses were performed using IBM SPSS (version 22.0; IBM, Armonk, NY, USA) and SAS (version 9.4; SAS Institute, Cary, NC, USA).

\section{Results}

A total of 304 patients underwent PD during the study period. Three patients with missing data were excluded from this study. The demographic data of the remaining 301 patients are presented in Table 1. Of the patients, 97.06\% had American Society of Anesthesiologists physical status grade 2 or 3 and $60.14 \%$ underwent standard PD without vessel resection. Pancreatic adenocarcinoma was the most common pathologic type, with an incidence of $36.95 \%$. The proportion of patients who underwent R0 resection for malignancy was $90.45 \%$.

The postoperative morbidity rate in the cohort was $56.48 \%$, and the morbidities were predominantly Clavien-Dindo grades III and IV (Table 2). The most common complication was POPF, followed by DGE. The mortality rate was $3.65 \%$. Fifteen patients required a reoperation.

The fluid intake during the first $24 \mathrm{~h}$ after surgery ranged from 1790 to $13,464 \mathrm{~mL}$, and the output ranged from 700 to $5600 \mathrm{~mL}$. The fluid intake during the $24-48-\mathrm{h}$ postoperative period ranged from 2231 to $9804 \mathrm{~mL}$, and the output ranged from 1095 to $7365 \mathrm{~mL}$. The fluid intake during the 48-72-h postoperative period ranged from 750 to $18,299 \mathrm{~mL}$, and the output ranged from 985 to $7205 \mathrm{~mL}$. Lastly, the fluid intake during the 72-96-h postoperative period ranged from 750 to $14,584 \mathrm{~mL}$, and the output ranged from 476 to $7244 \mathrm{~mL}$.

Univariate analysis revealed that patients in the higher quartiles of fluid balance were more likely to have higher morbidity rates and longer hospital and ICU LOS in the 0-24-, 24-48-, and 48-72-h postoperative periods than those in the lower quartiles; however, no significant differences were found in these parameters according to fluid balance in the 72-96-h postoperative period (Tables 3 and 4, Supplementary Tables 1 and 2). Additionally, compared with patients in the two lowest quartiles of fluid balance, those in the two highest quartiles had significantly higher mortality rates in the $24-48$-h postoperative period, with trends toward increased incidences of POPF, DGE, SIRS, ARDS, hemorrhage, and heart failure and significant increases in these incidences in the 48-72-h postoperative period. After adjusting for the individual body surface area, the same trends were observed. Compared with patients in the first and second quartiles of fluid balance, those in the third and fourth quartiles had significantly higher incidences of POPF, DGE, SIRS, ARDS, hemorrhage, and heart failure in the 24-48- and 48-72-h postoperative periods.

Receiver operating characteristic curves were created to evaluate the relationship between fluid balance 
Table 1 Patient Demographics and Preoperative Variables $(n=301)$

\begin{tabular}{|c|c|c|c|c|c|}
\hline \multirow[b]{2}{*}{ Characteristics } & \multirow[b]{2}{*}{ Total } & \multicolumn{4}{|c|}{ Fluid balance quartile } \\
\hline & & $1 \mathrm{st}$ & 2nd & $3 \mathrm{rd}$ & 4 th \\
\hline Age $(y r)$, mean $\pm S D$ & $55.43 \pm 10.90$ & $54.85 \pm 12.26$ & $54.70 \pm 11.38$ & $56.79 \pm 9.60$ & $55.37 \pm 10.26$ \\
\hline \multicolumn{6}{|l|}{ Gender } \\
\hline Female & $155(51.45)$ & $37(49.33)$ & $41(53.95)$ & $35(46.67)$ & $42(56.00)$ \\
\hline Male & $146(48.55)$ & $38(50.67)$ & $35(46.05)$ & $40(53.33)$ & $33(44.00)$ \\
\hline Weight $(\mathrm{kg})$, mean $\pm \mathrm{SD}$ & $58.24 \pm 10.10$ & $58.61 \pm 10.44$ & $57.59 \pm 10.33$ & $58.15 \pm 9.60$ & $58.61 \pm 10.18$ \\
\hline $\mathrm{BMI}\left(\mathrm{kg} / \mathrm{m}^{2}\right)$, mean $\pm \mathrm{SD}$ & $21.62 \pm 3.07$ & $21.65 \pm 3.18$ & $21.57 \pm 2.94$ & $21.54 \pm 2.94$ & $21.74 \pm 3.25$ \\
\hline Surface area $\left(\mathrm{m}^{2}\right)$ & $1.69 \pm 0.19$ & $1.70 \pm 0.19$ & $1.67 \pm 0.20$ & $1.69 \pm 0.18$ & $1.69 \pm 0.18$ \\
\hline \multicolumn{6}{|l|}{ ASA class } \\
\hline 1 & $9(2.94)$ & $2(2.67)$ & $4(5.26)$ & $2(2.67)$ & $1(1.33)$ \\
\hline 2 & $121(40.15)$ & $32(42.67)$ & $31(40.79)$ & $30(40.00)$ & $28(37.33)$ \\
\hline 3 & $171(56.91)$ & $41(54.67)$ & $41(53.95)$ & $43(57.33)$ & $46(61.33)$ \\
\hline \multicolumn{6}{|l|}{ Preoperative biliary drainage } \\
\hline Yes & $101(33.54)$ & $27(36.00)$ & $25(32.89)$ & $26(34.67)$ & $23(30.67)$ \\
\hline No & $200(66.46)$ & $48(64.00)$ & $51(67.11)$ & $49(65.33)$ & $52(69.33)$ \\
\hline \multicolumn{6}{|l|}{ Surgical procedure } \\
\hline Standard PD & $181(60.14)$ & $49(65.33)$ & $46(60.53)$ & $45(60.00)$ & $41(54.67)$ \\
\hline Extended PD & $68(22.54)$ & $16(21.33)$ & $17(22.37)$ & $15(20.00)$ & $20(26.67)$ \\
\hline PPPD & $52(17.25)$ & $10(13.33)$ & $13(17.11)$ & $15(20.00)$ & $14(18.67)$ \\
\hline \multicolumn{6}{|l|}{ Vascular resection } \\
\hline Yes & $56(18.50)$ & $12(16.00)$ & $13(17.11)$ & $14(18.67)$ & $17(22.67)$ \\
\hline No & $245(81.50)$ & $63(84.00)$ & $63(82.89)$ & $61(81.33)$ & $58(77.33)$ \\
\hline \multicolumn{6}{|l|}{ Pathological evidence } \\
\hline Pancreatic adenocarcinoma & $111(36.95)$ & $31(41.33)$ & $22(28.95)$ & $30(40.00)$ & $28(37.33)$ \\
\hline Pancreatic neuroendocrine tumor & $10(3.32)$ & $4(5.33)$ & $2(2.63)$ & $3(4.00)$ & $1(1.33)$ \\
\hline IPMN & $9(2.99)$ & $3(4.00)$ & $3(3.95)$ & $1(1.33)$ & $2(2.67)$ \\
\hline Ampullary adenocarcinoma & $37(12.29)$ & $5(6.67)$ & $10(13.16)$ & $12(16.00)$ & $10(13.33)$ \\
\hline Ampullary adenoma & $35(11.63)$ & $8(10.67)$ & $11(14.47)$ & $7(9.33)$ & $9(12.00)$ \\
\hline Duodenal adenocarcinoma & $55(18.27)$ & $16(21.33)$ & $14(18.42)$ & $10(13.33)$ & $15(20.00)$ \\
\hline Cholangiocarcinoma & $17(5.65)$ & $4(5.33)$ & $3(3.95)$ & $4(5.33)$ & $6(8.00)$ \\
\hline Mass-forming pancreatitis & $19(6.31)$ & $3(4.00)$ & $8(10.53)$ & $6(8.00)$ & $2(2.67)$ \\
\hline Other & $8(2.66)$ & $1(1.33)$ & $3(3.95)$ & $2(2.67)$ & $2(2.67)$ \\
\hline \multicolumn{6}{|l|}{ Tumor type } \\
\hline Benign & $81(26.91)$ & $19(25.33)$ & $27(35.53)$ & $19(25.33)$ & $16(21.33)$ \\
\hline Malignant & $220(73.09)$ & $56(74.67)$ & 49 (64.47) & $56(74.67)$ & $59(78.67)$ \\
\hline \multicolumn{6}{|l|}{ Grade ( $n=220$ malignancies) } \\
\hline High & $65(29.54)$ & $23(30.67)$ & $7(9.21)$ & $11(14.67)$ & $24(32.00)$ \\
\hline Moderate & $112(50.91)$ & $24(32.00)$ & $31(40.79)$ & $31(41.33)$ & $26(34.67)$ \\
\hline Low & $35(15.91)$ & $8(10.67)$ & $9(11.84)$ & $11(14.67)$ & $7(9.33)$ \\
\hline Not defined & $8(3.64)$ & $1(1.33)$ & $2(2.63)$ & $3(4.00)$ & $2(2.67)$ \\
\hline \multicolumn{6}{|l|}{ Stage ( $n=220$ malignancies $)$} \\
\hline 0 & 0 & 0 & 0 & 0 & 0 \\
\hline IA & $10(4.55)$ & $3(4.00)$ & $2(2.63)$ & $3(4.00)$ & $2(2.63)$ \\
\hline IB & $16(7.27)$ & $5(6.67)$ & $4(5.26)$ & $2(2.67)$ & $5(6.67)$ \\
\hline IIA & $32(14.55)$ & $9(12.00)$ & $6(7.89)$ & $9(12.00)$ & $8(10.67)$ \\
\hline IIB & $117(53.18)$ & $29(38.67)$ & $27(35.53)$ & $29(38.67)$ & $32(42.67)$ \\
\hline III & $22(10.00)$ & $4(5.33)$ & $5(6.58)$ & $7(9.33)$ & $6(8.00)$ \\
\hline IV & $7(3.18)$ & $1(1.33)$ & $1(1.32)$ & $3(4.00)$ & $2(2.67)$ \\
\hline Not defined & $16(7.27)$ & $5(6.67)$ & $4(5.26)$ & $3(4.00)$ & $4(5.33)$ \\
\hline \multicolumn{6}{|l|}{ Resection margin ( $n=220$ malignancies $)$} \\
\hline R0 & $199(90.45)$ & $52(92.86)$ & $42(85.71)$ & $51(91.07)$ & $54(91.53)$ \\
\hline $\mathrm{R} 1$ & $21(9.55)$ & $4(7.14)$ & $7(14.2)$ & $5(8.93)$ & $5(8.47)$ \\
\hline
\end{tabular}

ASA, American Society of Anesthesiologists; BMI, body mass index; IPMN, intraductal papillary mucinous neoplasms. Data presented with Number (percentage) or Mean \pm SD 
Table 2 Postoperative outcomes

\begin{tabular}{|c|c|}
\hline \multicolumn{2}{|l|}{ Outcome } \\
\hline Morbidity & $170(56.48)$ \\
\hline Mortality & $11(3.65)$ \\
\hline Length of stay $(d)$, mean $\pm S D$ & $25.9 \pm 10.9$ \\
\hline ICU length of stay $(\mathrm{d})$, mean \pm SD & $5.5 \pm 2.9$ \\
\hline Postoperative 0-24-h input (ml), mean (range) & $3973(1790-13,464$ \\
\hline Postoperative $24-48-\mathrm{h}$ input $(\mathrm{ml})$, mean (range) & $4922(2231-9804)$ \\
\hline Postoperative 48-72-h input (ml), mean (range) & $3383(750-18,299)$ \\
\hline Postoperative $72-96-\mathrm{h}$ input $(\mathrm{ml})$, mean (range) & $4355(750-14,585)$ \\
\hline Postoperative $0-24-\mathrm{h}$ output $(\mathrm{ml})$, mean (range) & $2400(700-5600)$ \\
\hline $\begin{array}{l}\text { Postoperative } 24-48 \text {-h output (ml), mean } \\
\text { (range) }\end{array}$ & $3369(1095-7365)$ \\
\hline $\begin{array}{l}\text { Postoperative } 48-72 \text {-h output (ml), mean } \\
\text { (range) }\end{array}$ & $3894(985-7205)$ \\
\hline $\begin{array}{l}\text { Postoperative } 72-96-\mathrm{h} \text { output (ml), mean } \\
\text { (range) }\end{array}$ & $4157(476-7244)$ \\
\hline Clavien Grade III & $136(45.18)$ \\
\hline Clavien Grade IV & $34(11.30)$ \\
\hline Surgical site infection & $45(14.95)$ \\
\hline Pancreatic fistula & $96(31.89)$ \\
\hline Grade A & $71(23.59)$ \\
\hline Grade $\mathrm{B} / \mathrm{C}$ & $25(8.31)$ \\
\hline Bile leakage & $4(1.33)$ \\
\hline Bowel leakage & $5(1.66)$ \\
\hline Delayed gastric emptying & $95(31.56)$ \\
\hline Grade A & $63(20.93)$ \\
\hline Grade B & $23(7.64)$ \\
\hline Grade $\mathrm{C}$ & $9(2.99)$ \\
\hline SIRS & $85(28.24)$ \\
\hline ARDS & $34(11.30)$ \\
\hline Acute kidney injury & $9(2.99)$ \\
\hline Hemorrhage & $65(21.59)$ \\
\hline Heart failure/ Myocardial ischemia & $23(7.64)$ \\
\hline Thrombosis & $2(0.66)$ \\
\hline Hospital readmit & $76(25.25)$ \\
\hline Reoperation & 15 (4.98) \\
\hline
\end{tabular}

ARDS, acute respiratory distress syndrome; SIRS, systemic inflammatory response syndrome. Data presented with Number (percentage), Mean \pm SD or Mean (range)

and morbidity at each postoperative time interval. The areas under the curve for the 0-24-, 24-48-, 48-72-, and 72-96-h postoperative periods were $0.62,0.66,0.67$, and 0.56 , respectively $(P=0.001, P<0.001, \mathrm{P}<0.001$, and $P=0.095$, respectively). Sensitivity and specificity testing for each period was performed to determine the best cutoff point for discriminating between excessive and non-excessive fluid balance. The optimal fluid balance values were $1730 \mathrm{~mL}$ for the 0-24-h postoperative period (sensitivity, $55.30 \%$; specificity, $64.89 \%$ ), $1684 \mathrm{~mL}$ for the $24-48-\mathrm{h}$ postoperative period (sensitivity, $56.47 \%$; specificity,
$69.47 \%$ ), and $616 \mathrm{~mL}$ for the $48-72$-h postoperative period (sensitivity, 68.24\%; specificity, 59.54\%) (Fig. 1A). When the overall fluid balance in the $0-72$-h postoperative period was considered, the area under the curve was $0.71(0.65-0.77)$ and the optimal fluid balance value that discriminated hospital morbidity was $4212 \mathrm{~mL}$ (sensitivity, 58.24\%; specificity, 77.10\%) (Fig. 1B). Patients with an excessive overall fluid balance in the $0-72$-h postoperative period had a higher hospital morbidity rate than those with a non-excessive fluid balance (76.7\% vs. $41.3 \%$, $P<0.001)$.

\section{Discussion}

The negative effects of excessive fluid overload in the postoperative period have long been recognized [13-16]. A contemporary randomized study investigating fluid regimens in patients undergoing colorectal surgery found that a restrictive fluid strategy not only led to decreased cardiopulmonary morbidity but also reduced the incidence of tissue-healing complications [17]. Similarly, a recent prospective cohort study that focused on major surgeries found that patients with an excessive intraoperative fluid balance had higher hospital mortality rates than those with a non-excessive intraoperative fluid balance [18].

The present study examined the role of postoperative fluid balance in patients undergoing PD, with a focus on four consecutive postoperative time intervals. Compared with patients in the lower quartiles of fluid balance, those in the higher quartiles had increased incidences of POPF, hemorrhage, DGE, ARDS, SIRS, and overall morbidity, in addition to longer ICU and hospital LOS. The differences in the incidences of these adverse events according to fluid balance quartiles were more pronounced in the 24-48- and 48-72-h postoperative periods. The same conclusions were obtained after adjusting for the individual body surface area.

Various studies have discussed how to best regulate and manage fluid balance during the perioperative period, and the recommendations have changed from the initial regimen of liberal fluid intake to the currently used restricted fluid balance regimen [19]. Many studies have focused on whether perioperative fluid balance management or maintenance of a positive or negative fluid balance in the early postoperative period positively or negatively affects the morbidity and mortality rates in abdominal surgery [20-22]. The present results demonstrated a morbidity rate of $56.48 \%$ in the entire cohort of patients who underwent PD, with a rate of $76.00 \%$ in the highest quartile of fluid balance in the 0-72-h postoperative period compared with $38.67 \%$ in the lowest quartile. Additional analyses about the timing of morbidities indicated that patients with early postoperative complications received more fluid. Only $18 \%$ of morbidities (31 of 170) 
Table 3 Surgical outcomes by 48-h fluid balance quartiles with surface area adjustment

\begin{tabular}{|c|c|c|c|c|c|c|c|c|c|c|}
\hline & \multicolumn{5}{|c|}{ 48-h fluid balance } & \multicolumn{5}{|c|}{ 48-h fluid balance (SA adjustment) } \\
\hline & 1 st & 2 nd & $3 \mathrm{rd}$ & 4 th & $p$ value & $1 \mathrm{st}$ & 2 nd & $3 \mathrm{rd}$ & 4 th & $\mathrm{p}$ value \\
\hline Morbidity & 28 & 41 & 43 & 58 & $<0.001$ & 28 & 42 & 44 & 56 & $<0.001$ \\
\hline Mortality & 0 & 1 & 5 & 5 & 0.051 & 0 & 1 & 3 & 7 & 0.014 \\
\hline Hospital LOS & $23.8 \pm 10.0$ & $24.1 \pm 11.2$ & $26.5 \pm 10.2$ & $29.0 \pm 11.8$ & 0.012 & $23.6 \pm 9.7$ & $25.0 \pm 11.8$ & $26.3 \pm 9.9$ & $28.6 \pm 11.9$ & 0.036 \\
\hline ICU LOS & $4.7 \pm 2.0$ & $4.9 \pm 2.7$ & $6.0 \pm 3.4$ & $6.4 \pm 2.9$ & $<0.001$ & $4.7 \pm 2.0$ & $5.1 \pm 2.8$ & $5.6 \pm 3.0$ & $6.6 \pm 3.3$ & $<0.001$ \\
\hline SSI & 11 & 14 & 10 & 10 & 0.793 & 11 & 15 & 8 & 11 & 0.482 \\
\hline POPF & 16 & 21 & 27 & 32 & 0.028 & 16 & 22 & 27 & 31 & 0.051 \\
\hline Bile leakage & 0 & 3 & 1 & 0 & 0.112 & 0 & 3 & 0 & 1 & 0.112 \\
\hline Bowel leakage & 2 & 1 & 1 & 1 & 0.892 & 2 & 1 & 1 & 1 & 0.892 \\
\hline DGE & 13 & 18 & 28 & 36 & $<0.001$ & 13 & 17 & 31 & 34 & $<0.001$ \\
\hline SIRS & 5 & 16 & 24 & 40 & $<0.001$ & 5 & 16 & 25 & 39 & $<0.001$ \\
\hline ARDS & 2 & 7 & 10 & 15 & 0.008 & 2 & 7 & 10 & 15 & 0.008 \\
\hline AKI & 1 & 1 & 5 & 2 & 0.174 & 1 & 1 & 3 & 4 & 0.372 \\
\hline Hemorrhage & 8 & 10 & 14 & 33 & $<0.001$ & 8 & 12 & 14 & 31 & $<0.001$ \\
\hline HF/MI & 0 & 1 & 7 & 15 & $<0.001$ & 0 & 2 & 5 & 16 & $<0.001$ \\
\hline Liver failure & 1 & 2 & 8 & 6 & 0.041 & 1 & 4 & 4 & 8 & 0.102 \\
\hline Thrombosis & 0 & 1 & 1 & 0 & 0.572 & 0 & 1 & 1 & 0 & 0.572 \\
\hline Readmission & 14 & 19 & 15 & 28 & 0.035 & 13 & 19 & 16 & 28 & 0.031 \\
\hline Reoperation & 1 & 2 & 3 & 9 & 0.012 & 1 & 2 & 4 & 8 & 0.040 \\
\hline
\end{tabular}

AKI, acute kidney injury; ARDS, acute respiratory distress syndrome; DGE, delayed gastric emptying; HF, heart failure; ICU, intensive care unit; LOS, length of stay; MI, myocardial infarction; POPF, postoperative pancreatic fistula; SA, surface area; SIRS, systemic inflammatory response syndrome; SSI, surgical site infection

Table 4 Surgical outcomes by 72-h fluid balance quartiles with surface area adjustment

\begin{tabular}{|c|c|c|c|c|c|c|c|c|c|c|}
\hline & \multicolumn{5}{|c|}{ 72-h fluid balance } & \multicolumn{5}{|c|}{ 72-h fluid balance (SA adjustment) } \\
\hline & $1 \mathrm{st}$ & 2nd & $3 r d$ & 4 th & $\mathrm{p}$ value & 1 st & 2 nd & $3 \mathrm{rd}$ & 4 th & $\mathrm{p}$ value \\
\hline Morbidity & 29 & 37 & 47 & 57 & $<0.001$ & 29 & 40 & 44 & 57 & $<0.001$ \\
\hline Mortality & 0 & 1 & 2 & 8 & 0.002 & 1 & 0 & 1 & 9 & $<0.001$ \\
\hline Hospital LOS & $22.3 \pm 9.3$ & $26.8 \pm 9.3$ & $26.9 \pm 12.8$ & $27.3 \pm 11.6$ & 0.014 & $22.4 \pm 9.3$ & $26.5 \pm 9.2$ & $27.1 \pm 12.9$ & $27.4 \pm 11.5$ & 0.015 \\
\hline ICU LOS & $4.4 \pm 2.4$ & $5.0 \pm 2.1$ & $5.5 \pm 2.8$ & $7.0 \pm 3.4$ & $<0.001$ & $4.5 \pm 2.5$ & $5.2 \pm 2.1$ & $5.2 \pm 2.3$ & $7.2 \pm 2.9$ & $<0.001$ \\
\hline SSI & 8 & 10 & 18 & 9 & 0.085 & 8 & 10 & 17 & 10 & 0.176 \\
\hline POPF & 17 & 18 & 25 & 36 & 0.002 & 17 & 19 & 23 & 37 & 0.002 \\
\hline Bile leakage & 2 & 0 & 1 & 1 & 0.563 & 2 & 0 & 1 & 1 & 0.563 \\
\hline Bowel leakage & 1 & 2 & 2 & 0 & 0.528 & 1 & 2 & 2 & 0 & 0.528 \\
\hline DGE & 16 & 20 & 24 & 35 & 0.006 & 15 & 21 & 23 & 36 & 0.002 \\
\hline SIRS & 8 & 17 & 20 & 40 & $<0.001$ & 8 & 17 & 19 & 41 & $<0.001$ \\
\hline ARDS & 2 & 4 & 9 & 19 & $<0.001$ & 2 & 5 & 7 & 20 & $<0.001$ \\
\hline AKI & 0 & 1 & 1 & 7 & 0.003 & 0 & 2 & 0 & 7 & 0.002 \\
\hline Hemorrhage & 7 & 13 & 16 & 29 & $<0.001$ & 7 & 13 & 15 & 30 & $<0.001$ \\
\hline HF/MI & 1 & 1 & 2 & 19 & $<0.001$ & 1 & 1 & 1 & 20 & $<0.001$ \\
\hline Liver failure & 2 & 1 & 4 & 10 & 0.007 & 2 & 1 & 3 & 11 & 0.001 \\
\hline Thrombosis & 1 & 0 & 1 & 0 & 0.567 & 1 & 0 & 1 & 0 & 0.567 \\
\hline Readmission & 12 & 17 & 20 & 27 & 0.038 & 12 & 17 & 20 & 27 & 0.038 \\
\hline Reoperation & 1 & 1 & 5 & 8 & 0.020 & 1 & 1 & 5 & 8 & 0.020 \\
\hline
\end{tabular}

AKI, acute kidney injury; ARDS, acute respiratory distress syndrome; DGE, delayed gastric emptying; HF, heart failure; ICU, intensive care unit; LOS, length of stay; MI, myocardial infarction; POPF, postoperative pancreatic fistula; SA, surface area; SIRS, systemic inflammatory response syndrome; SSI, surgical site infection 

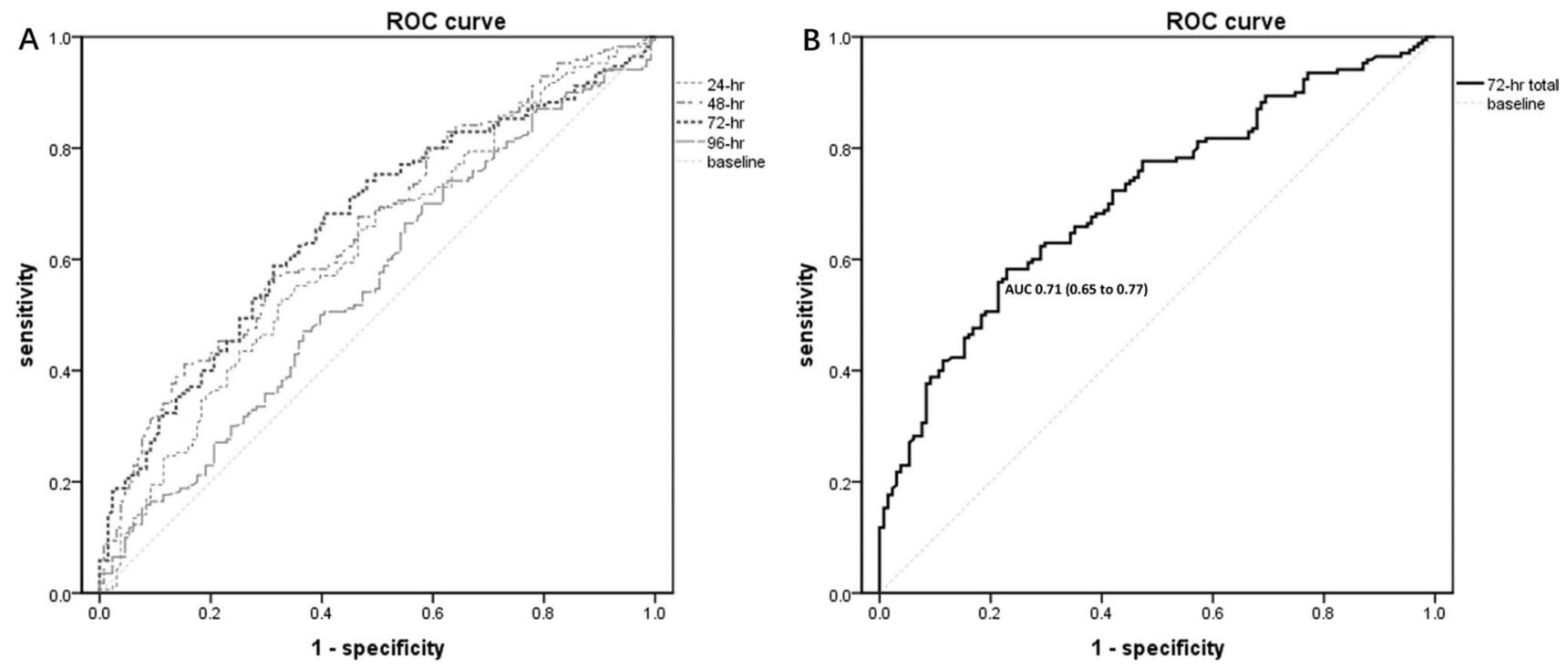

Fig. 1 Receiver operating characteristic (ROC) curves of fluid balance for the prediction of morbidities. (A) Fluid balance ROC curve for each period (postoperative 24, 48, 72, and $96 \mathrm{~h}$ ). (B) Fluid balance ROC curve for the total postoperative 72-h interval

were suspected or diagnosed within the first $72 \mathrm{~h}$ after surgery. This suggests that a higher fluid balance, rather than a larger fluid volume received, was associated with a higher incidence of morbidities.. In other words, failure to mobilize fluid may be an early indicator of impending complications.

POPF is a major concern after PD. In our study, the incidence of POPF was higher in patients in the higher quartiles of fluid balance than in those in the lower quartiles throughout the entire $0-72$-h postoperative period. This trend was particularly obvious in the 48-72-h period, during which nearly half of the patients ( 36 of 75) in the highest quartile of fluid balance had POPF compared to less than a quarter of patients in the lowest quartile (17 of 75). It seemed that a higher fluid balance after PD was associated with a higher POPF rate, which was consistent with the findings reported by Wang et al. [23]

In 1972, an animal study showed that increasing the fluid balance aggravates tissue edema, which impairs oxygen diffusion, decreases tissue oxygen tension, and leads to worse healing [24]. Another study reported that the quantity of infusion significantly affects the functional and structural stability of intestinal anastomoses in the early postoperative period, particularly from postoperative days 3 to 5 [25]. As the stability and quality of intestinal anastomosis influence the insufficiency rate, volume overload may have deleterious effects on anastomotic healing and postoperative complications in digestive surgery because of marked bowel wall edema. Thus, restricting fluid balance may decrease the degree of bowel edema, which would benefit anastomotic healing to some extent.

Excessive fluid intake is associated with cardiopulmonary events after a major surgery. A perioperative positive fluid balance of $>2000 \mathrm{~mL}$ has been reported to increase the risk of cardiovascular complications by 2.5 times [26]. In the current study, patients in the highest quartile of fluid balance had a much higher incidence of heart failure or myocardial infarction in the 24-48- and 48-72-h postoperative periods than those in the lower quartiles. Although fluid administration can increase cardiac output, an excessive amount of fluid can subsequently depress ventricular function and increase cardiac morbidity [27]. Furthermore, surgical trauma increases the permeability of the capillaries, leading to a large amount of exudation. Our data revealed that $11.30 \%$ of the patients who underwent PD developed ARDS postoperatively. Unsurprisingly, patients in the higher quartiles of fluid balance were more likely to develop ARDS in the 0-24-, 24-48-, and 48-72-h postoperative periods than those in the lower quartiles. A previous study reported that the adverse effects of volume overload are more evident in the lungs, where fluid resuscitation can lead to acute pulmonary edema, compromising gas exchange and increasing the patient's susceptibility to infection. Additionally, pulmonary function may be impaired by the accumulation of interstitial fluid, which can contribute to the development of pulmonary edema, atelectasis, pneumonia, or even respiratory failure. ${ }^{28}$

The present study had some limitations. First, this was a single-center retrospective analysis; thus, the inherent bias in this type of research should be considered. Second, daily weight changes were not thoroughly investigated, although such data can also provide evidence of the degree of fluid overload and can be used to scrutinize the results. Third, the effects of fluid type (crystalloid, colloid, or blood products) and quantitative data on fluid intake were not evaluated. 


\section{Conclusion}

The present study investigated a large cohort of patients who underwent PD and found that an increased fluid balance in the early postoperative period ( $0-72 \mathrm{~h}$ after surgery) was associated with increased incidences of overall morbidity, POPF, DGE, and ARDS, as well as longer hospital and ICU LOS. In patients with a high postoperative fluid balance, particularly in the first few days, surgeons should pay close attention to the occurrence of complications.

Supplementary Information The online version contains supplementary material available at https://doi.org/10.1007/s00423-022-02443-6.

Acknowledgments We specially thank Kelly Zammit, BVSc, from Liwen Bianji, Edanz Editing China (www.liwenbianji.cn/ac) and Gerlyn from Wiley Editing Services (en.wileyeditingservices.com/) for language editing of this manuscript.

Authors' contributions Chao Dang and Renyi Qin conceived and designed the study. Hang Zhang and Yechen Feng performed the data acquisition. Yechen Feng and Duoji Suolang interpreted and analyzed the data. All the authors drafted the manuscript. Renyi Qin critically revised this manuscript.

Funding This study was funded by Tongji Hospital Clinical Research Flagship Program 2019CR203.

\section{Declarations}

Conflict of interest The authors declare no conflicts of interest.

Ethical approval All procedures performed in studies involving human participants were in accordance with the ethical standards of the institutional research committee and with the 1964 Helsinki Declaration and its later amendments or comparable ethical standards. The study was approved by the Tongji Hospital Instituitional Review Board.

Open Access This article is licensed under a Creative Commons Attribution 4.0 International License, which permits use, sharing, adaptation, distribution and reproduction in any medium or format, as long as you give appropriate credit to the original author(s) and the source, provide a link to the Creative Commons licence, and indicate if changes were made. The images or other third party material in this article are included in the article's Creative Commons licence, unless indicated otherwise in a credit line to the material. If material is not included in the article's Creative Commons licence and your intended use is not permitted by statutory regulation or exceeds the permitted use, you will need to obtain permission directly from the copyright holder. To view a copy of this licence, visit http://creativecommons.org/licenses/by/4.0/.

\section{References}

1. Kimura W, Miyata H, Gotoh M, Hirai I, Kenjo A, Kitagawa Y et al (2014) A pancreaticoduodenectomy risk model derived from 8575 cases from a national single-race population (Japanese) using a web-based data entry system: the 30-day and in-hospital mortality rates for pancreaticoduodenectomy. Ann Surg 259(4):773-780
2. Andrianello S, Marchegiani G, Malleo G, Masini G, Balduzzi A, Paiella S, et al. (2020) Pancreaticojejunostomy with externalized stent vs Pancreaticogastrostomy with externalized stent for patients with high-risk pancreatic anastomosis: a single-center, phase 3, Randomized Clinical Trial. JAMA Surg

3. Lowy AM, Lee JE, Pisters PW, Davidson BS, Fenoglio CJ, Stanford P et al (1997) Prospective, randomized trial of octreotide to prevent pancreatic fistula after pancreaticoduodenectomy for malignant disease. Ann Surg 226(5):632-641

4. Chiba N, Ochiai S, Yokozuka K, Gunji T, Sano T, Tomita K et al (2019) Risk factors for life-threatening grade C postoperative pancreatic fistula after Pancreatoduodenectomy compared to grade B. Anticancer Res 39(4):2199-2205

5. Dembinski J, Mariette C, Tuech JJ, Mauvais F, Piessen G, Fuks D et al (2019) Early removal of intraperitoneal drainage after pancreatoduodenectomy in patients without postoperative fistula at POD3: results of a randomized clinical trial. J Visc Surg 156(2):103-112

6. Senda Y, Shimizu Y, Natsume S, Ito S, Komori K, Abe T et al (2018) Randomized clinical trial of duct-to-mucosa versus invagination pancreaticojejunostomy after pancreatoduodenectomy. Br J Surg 105(1):48-57

7. Shires T, Williams J, Brown F (1961) Acute change in extracellular fluids associated with major surgical procedures. Ann Surg 154:803-810

8. Dindo D, Demartines N, Clavien PA (2004) Classification of surgical complications: a new proposal with evaluation in a cohort of 6336 patients and results of a survey. Ann Surg 240(2):205-213

9. Bassi C, Marchegiani G, Dervenis C, Sarr M, Abu Hilal M, Adham M et al (2017) The 2016 update of the international study group (ISGPS) definition and grading of postoperative pancreatic fistula: 11 years after. Surgery 161(3):584-591

10. Wente MN, Bassi C, Dervenis C, Fingerhut A, Gouma DJ, Izbicki JR et al (2007) Delayed gastric emptying (DGE) after pancreatic surgery: a suggested definition by the international study Group of Pancreatic Surgery (ISGPS). Surgery 142(5):761-768

11. Bone RC, Balk RA, Cerra FB, Dellinger RP, Fein AM, Knaus WA et al (1992) Definitions for sepsis and organ failure and guidelines for the use of innovative therapies in sepsis. The ACCP/ SCCM consensus conference committee. American College of Chest Physicians/Society of Critical Care Medicine. Chest 101(6):1644-1655

12. Force ADT, Ranieri VM, Rubenfeld GD, Thompson BT, Ferguson ND, Caldwell E et al (2012) Acute respiratory distress syndrome: the Berlin definition. JAMA 307(23):2526-2533

13. Awad S, Allison SP, Lobo DN (2008) The history of $0.9 \%$ saline. Clin Nutr 27(2):179-188

14. Kulemann B, Fritz M, Glatz T, Marjanovic G, Sick O, Hopt UT, Hoeppner J, Makowiec F (2017) Complications after pancreaticoduodenectomy are associated with higher amounts of intra- and postoperative fluid therapy: a single center retrospective cohort study. Ann Med Surg (Lond) 27(16):23-29

15. Åkerberg D, Ansari D, Bergenfeldt M, Andersson R, Tingstedt B (2019) Early postoperative fluid retention is a strong predictor for complications after pancreatoduodenectomy. HPB (Oxford) 21(12):1784-1789

16. Garland ML, Mace HS, MacCormick AD, McCluskey SA, Lightfoot NJ (2019 Jun) Restrictive versus Liberal fluid regimens in patients undergoing Pancreaticoduodenectomy: a systematic review and Meta-analysis. J Gastrointest Surg 23(6):1250-1265

17. Brandstrup B, Tonnesen H, Beier-Holgersen R, Hjortso E, Ording $\mathrm{H}$, Lindorff-Larsen $\mathrm{K}$ et al (2003) Effects of intravenous fluid restriction on postoperative complications: comparison of two perioperative fluid regimens: a randomized assessor-blinded multicenter trial. Ann Surg 238(5):641-648 
18. Miller TE, Roche AM, Mythen M (2015) Fluid management and goal-directed therapy as an adjunct to enhanced recovery after surgery (ERAS). Canadian journal of anaesthesia $=$. J Can D'anesthesie 62(2):158-168

19. Holte K, Klarskov B, Christensen DS, Lund C, Nielsen KG, Bie $P$ et al (2004) Liberal versus restrictive fluid administration to improve recovery after laparoscopic cholecystectomy: a randomized, double-blind study. Ann Surg 240(5):892-899

20. Jia FJ, Yan QY, Sun Q, Tuxun T, Liu H, Shao L (2017) Liberal versus restrictive fluid management in abdominal surgery: a metaanalysis. Surg Today 47(3):344-356

21. Raghunathan K, Singh M, Lobo DN (2015) Fluid management in abdominal surgery: what, when, and when not to administer. Anesthesiol Clin 33(1):51-64

22. Lavu H, Sell NM, Carter TI, Winter JM, Maguire DP, Gratch DM et al (2014) The HYSLAR trial: a prospective randomized controlled trial of the use of a restrictive fluid regimen with $3 \%$ hypertonic saline versus lactated ringers in patients undergoing pancreaticoduodenectomy. Ann Surg 260(3):445-453 discussion 53-5

23. S Wang, X Wang, . Dai, J Han, N Li, J Li. The effect of intraoperative fluid volume administration on pancreatic fistulas after pancreaticoduodenectomy. J Investig Surg 2014; 27: 88-94
24. Heughan C, Ninikoski J, Hunt TK (1972) Effect of excessive infusion of saline solution on tissue oxygen transport. Surg Gynecol Obstet 135(2):257-260

25. Marjanovic G, Villain C, Juettner E, zur Hausen A, Hoeppner J, Hopt UT et al (2009) Impact of different crystalloid volume regimes on intestinal anastomotic stability. Ann Surg 249(2):181-185

26. Pipanmekaporn T, Punjasawadwong Y, Charuluxananan S, Lapisatepun W, Bunburaphong P, Patumanond J et al (2014) Incidence of and risk factors for cardiovascular complications after thoracic surgery for noncancerous lesions. J Cardiothorac Vasc Anesth 28(4):948-953

27. Silva JM Jr, de Oliveira AM, Nogueira FA, Vianna PM, Pereira Filho MC, Dias LF et al (2013) The effect of excess fluid balance on the mortality rate of surgical patients: a multicenter prospective study. Crit Care 17(6):R288

Publisher's note Springer Nature remains neutral with regard to jurisdictional claims in published maps and institutional affiliations. 